\title{
RECEPTIVITY TO MYSTERY: CULTIVATION, LOSS, AND SCIENTISM
}

\author{
IAN JAMES KIDD
}

Durham University

\begin{abstract}
The cultivation of receptivity to the mystery of reality is a central feature of many religious and philosophical traditions, both Western and Asian. This paper considers two contemporary accounts of receptivity to mystery those of David E. Cooper and John Cottingham - and considers them in light of the problem of loss of receptivity. I argue that a person may lose their receptivity to mystery by embracing what I call a scientistic stance, and the paper concludes by offering two possible responses to combating that stance and restoring the receptivity to mystery that it occludes.
\end{abstract}

Let us follow it up ... wherever it is to be found, in the lives of those around us ... If we do so we shall find we are dealing with something for which there is only one appropriate expression, mysterium tremendum. The feeling of it may at times come sweeping like a gentle tide, pervading the mind with a tranquil mood of deepest worship. It may pass over into a more set and lasting attitude of the soul, continuing, as it were, thrillingly vibrant and resonant, until at last it dies away and the soul resumes its 'profane', non-religious mood of everyday experience. (Rudolf Otto) ${ }^{1}$

Understanding the idea of receptivity to mystery depends crucially on the notion or account of mystery in play. This paper focuses upon the sense of that term associated with various religious and spiritual traditions, including the practices, discourses and communities whose

\footnotetext{
${ }^{1}$ Rudolf Otto, The Idea of the Holy: An Inquiry Into the Non-rational Factor In the Idea of the Divine and Its Relation to the Rational, trans. J.W. Harvey (London: H. Milford/ Oxford University Press, 1923), pp. 12-13.
} 
purpose it is to articulate and perhaps induce experiences of mystery. Friedrich Schleiermacher, for instance, wrote that an aim of religious practice is to align the 'environment to which [one] belong[s]' with the 'universal source of spiritual life. Through such practical transformation, one's life becomes one of 'communion' with that source. ${ }^{2}$ Rudolf Otto also described an awareness of 'the presence of that which is a Mystery inexpressible', something present in both 'sudden, strong ebullitions of personal piety' and the 'fixed and ordered solemnities of rites', but which, if appropriately cultivated and responded to, is open to being 'developed into something beautiful and pure and glorious. ${ }^{3}$

These two testimonies help to indicate what I will call receptivity to mystery, and may either remind those who share such receptivity of it, or inspire those who do not - for, as later sections of the paper will indicate, such receptivity is not a universal feature of human beings' comportment within the world.

Since both experiences of mystery and their associated practices are too diverse to treat in any comprehensive sense, I focus here on their treatment by two contemporary philosophers, David E. Cooper and John Cottingham. Both affirm the central importance of 'experiences of mystery' and 'intimations of the transcendent', respectively, in religious life, even though they disagree on the nature of those experiences and intimations. But both agree on two points which are germane to my interests here. The first is that those experiences - of mystery or of transcendence - can sponsor forms of religious life; hence Cooper argues that 'living with mystery [is] a form of religious life', while Cottingham defends the claim that religiosity involves living in responsive awareness of the 'mystery of existence."

The second is that that both mystery and transcendence, different as they may be, are both vulnerable to a specific concern, one identified by both Cooper and Cottingham, which I will call loss of receptivity to mystery. That term offers three related tasks, each to be taken in turn. The first is to explain what Cooper and Cottingham mean by 'mystery' or 'transcendence', or which, for brevity's sake, I will refer to as a 'sense of

${ }^{2}$ Friedrich Schleiermacher, The Christian Faith, H.R. Mackintosh and J.S. Stewart (eds.) (Edinburgh: T\&T Clark, 1999), $\$ \$ 93.3$ and 6.2.

3 Rudolf Otto, The Idea of the Holy, pp. 12-13.

${ }^{4}$ David E. Cooper, 'Living with Mystery', p 13, and John Cottingham, 'Religion and the Mystery of Existence,', p. 31, both in the present volume. 
mystery'. It is that sense to which certain persons can become receptive. The second is to characterise such receptivity to mystery, as described by Cooper and Cottingham, including the practices through which it can be cultivated. The third then considers what the loss of such receptivity entails and, importantly, what might cause a person to lose it - and my focus will, following Cooper and Cottingham, be upon a prime suspect, which I'll call a 'scientistic stance'.

\section{MYSTERY AND TRANSCENDENCE}

It is worth beginning by noting some criticisms of these themes of mystery and transcendence. Those two terms are distinct from one another, as this section will indicate, but both arouse the suspicion or concern of many philosophers, a fact noted by both Cooper and Cottingham. The very idea of mystery is dismissed by two luminaries of contemporary philosophy - those being Richard Rorty and Hilary Putnam - on the grounds that it 'do[es] not get us anywhere' and that such a doctrine gives us no obvious reason to 'aim at' it. ${ }^{5}$ Indeed, it is not just mystery itself, but religion more widely, which has, perhaps, suffered from philosophical neglect. The philosophy of religion itself has suffered a contraction over the last few decades, such that we face, warns Cottingham, the 'genuine possibility' that religious thought and practice may vanish from the philosophical mainstream, 'brusquely dismissed or politely ignored' by those with avowed naturalistic commitments. ${ }^{6}$

The reasons for such sentiments are complex and since I discuss one of them - the 'scientistic stance' - later in the paper, they can be set aside for now. It is, however, worth my noting my agreement with Cooper's judgement that it would be 'hubris' to 'dismiss an idea' - that of receptivity to and living with a sense of mystery - that has featured centrally within 'spiritual traditions', ranging from Neo-platonism in Europe to Daoism in China. There is surely truth, too, in Cottingham's allied observation that such 'traditions of spirituality' have, since antiquity, 'served ... countless human beings' in their efforts to conceive and comport their lives. ${ }^{7}$

${ }^{5}$ Quoted and discussed in David E. Cooper, The Measure of Things: Humanism, Humility and Mystery (Oxford: Clarendon Press, 2002), pp. 281-282. This book is Cooper's most systematic account of his doctrine of mystery.

${ }^{6}$ John Cottingham, The Spiritual Dimension: Religion, Value and Human Life (Cambridge: Cambridge University Press, 2005), p. viii.

${ }^{7}$ Cooper, 'Living with Mystery', p. 8 and Cottingham, The Spiritual Dimension, p. 140. 
Perhaps few contemporary philosophers share or easily sympathise with the convictions and sensibilities reflected in those traditions, but that is poor reason to dismiss them. Indeed, once one appreciates that those same concerns continue to animate many persons today, the very idea of dismissing them surely becomes hubristic. It requires little exercise of historical or sociological prowess to recognise that experiences of mystery, including the sensibilities and concerns which gather around them, are deep and abiding features of the human condition.

Let me begin with Cooper, who in several recent writings has developed and defended a 'doctrine of mystery'. The central claim is that reality as it is, independently of human perspectives, is 'ineffable and mysterious', such that 'no account of the world ... could count as a description of reality as such', for any such description would be tied to the purposes, practices and perspectives of the creatures, whether human or not, which provided them. The doctrine of mystery which Cooper develops owes much to Buddhism, Daoism and the later Heidegger, amongst many others, indicating that it is not an 'abstract' doctrine - held on paper but never realised in practice - but is, rather, one which has 'played a central role in [the] moral and religious practice' of many cultures. Indeed, a sense of mystery has been one which 'reflective men and women', from Zhuangzi to Wittgenstein, have been 'apt to cultivate', owing to their recognition that the 'comportments' in which an experience of mystery is 'built-in' provide attractive 'ways of dealing [with and] dwelling' in the world. ${ }^{8}$ Such testimonies do not, of course, establish or prove a doctrine of mystery, but they should offset the initial scepticism of those critics who might doubt their very intelligibility.

The doctrine of mystery that Cooper offers is more sophisticated than this brief sketch can indicate, but enough has been said, for now, to indicate that a central feature of it is that it incorporates the possibility of one's having a 'sense of mystery' which shapes and informs one's life. A cultivated sense of the mysteriousness of reality effects a transformation of a person's attitudes, beliefs, and behaviour, both by liberating them from unwarrantedly hubristic doctrines and by inducing a sense of acute dependence upon what is beyond human understanding and control a claim which Cooper makes good on in other recent writings. ${ }^{9}$

\footnotetext{
${ }^{8}$ Cooper, The Measure of Things, pp. 281, 364, 358.

${ }^{9}$ As well as his 'Living with Mystery' in this volume, see also his 'Mystery, World and Religion', in Philosophers and God: At the Frontiers of Faith and Reason, ed. John
} 
Cottingham offers a related, though distinct set of claims, writing eloquently of 'aspirations and sensibilities', which he refers to as 'intimations of the transcendent'. Such intimations refer to 'something mysterious that transcends the boundaries of human comprehension', which Cottingham interprets theistically using the resources of Christian theology and the philosophies and poetries it has inspired. So when Wordsworth reported a 'presence that disturbs' him, inspiring 'elevated thoughts [and] a sense sublime', he testified to an intimation of the transcendent, in which the 'setting suns [and] blue sky' became 'deeply interfused' with the 'mind of man. ${ }^{10}$ Cottingham goes on to argue that the 'incorporation' of those intimations into a 'sustaining form of life' can 'enrich and transform' one's life. ${ }^{11}$

These intimations of the transcendent are not the peculiar property of certain privileged persons. For sure, those immersed in 'communities of praxis' which cultivate the requisite sensibilities may be more likely to enjoy them, but Cottingham stresses that they are part of the 'birthright' of all human beings. ${ }^{12}$ All of us, he suggests, feel expressions of 'yearnings deep within our nature' which 'cannot be entirely eradicated', or rendered mute. Indeed, they are the 'primal human existential response', the 'wellspring of spirituality', and the 'basis of the religious impulse.. ${ }^{13}$

It is important not to elide mystery and transcendence. Although there are parallels between Cooper and Cottingham's respective accounts - such as a sense of dependence on what is beyond the human' and corresponding hostility to 'hubristic' doctrines opposed to the cultivation of that sense - important differences remain between them. Most obviously, Cottingham is a theist and maintains that the transcendent is at least in principle open to human articulation, whereas

Cornwall and Michael McGhee (London: Continuum, 2009), pp. 51-62; and Convergence with Nature: A Daoist Perspective (Dartington: Green Books, 2012). Each of these works indicates how a sense of mystery can be cultivated and thereby inform a person's comportment within the world.

${ }^{10}$ William Wordsworth, Lines Written a Few Miles above Tintern Abbey [1798], in S. Gill (ed.), William Wordsworth: A Critical Edition of the Major Works (Oxford: Oxford University Press, 1984), ii., pp. 89-100. Quoted and discussed in John Cottingham, 'Our Natural Guide: Conscience, "Nature" and Moral Experience', in David S. Oderberg and Timothy Chappell (eds.), Human Values (London: Palgrave, 2004), pp. 11-31.

${ }^{11}$ Cottingham, The Spiritual Dimension, p. 171.

${ }^{12}$ Cottingham, The Spiritual Dimension, p. 35.

${ }^{13}$ Cottingham, 'Religion and the Mystery of Existence,' p. 19. 
Cooper insists that mystery is just that - mysterious and so unavailable even in principle to articulation and description.

Those concerned with the differences between Cooper's and Cottingham's accounts are invited to consult their own respective writings, but the concern I address in the remainder of this paper is one which applies both to mystery and to transcendence, however they are construed. For the scientistic stance that I will criticise applies to both those who deny mystery in Cooper's sense and those who deny a (perhaps effable) transcendence in Cottingham's sense; however, since 'mystery' carries fewer philosophical and theological connotations than transcendence, I will use that in the remainder of the paper.

\section{RECEPTIVITY TO MYSTERY}

Let me indicate three common features of Cooper's and Cottingham's accounts which are relevant to my discussion of loss of receptivity to mystery. The first is that 'mystery' refers to or involves something 'beyond the human', whether an undiscursible mystery or a transcendent reality. The second is that receptivity to mystery is strongly related to moral and spiritual transformation - ones which, as Cooper puts it, 'clear the mind' of a person from 'prejudices [and] ambitions' which 'deny ... space to the virtues' - thereby releasing those persons into ways of life which enjoy a 'natural consonance' with the world. ${ }^{14}$ Cottingham also identifies a sense of mystery, or transcendence, with liberation from false views, such as that the world is 'violent and depressing', 'coloured solely by our own human projections', or perhaps simply 'devoid of anything other than temporary and local significance. ${ }^{15}$

The third feature held in common by Cooper and Cottingham is the idea that receptivity to a sense of mystery can be cultivated by engaging in and with certain practices, communities and traditions. Many candidates are available, and in their works, Cooper and Cottingham survey some of the more representative examples, ranging from the apophatic tradition of Christian mysticism to Zen Buddhism. Alongside these overtly religious traditions, one should also include figures and traditions for whom the description 'religious' is more contestable. It strikes me that one can legitimately interpret Wittgenstein's remarks

\footnotetext{
${ }^{14}$ Cooper, 'Living with Mystery', p. 10.

${ }^{15}$ Cottingham, The Spiritual Dimension, p. 87.
} 
upon the 'miraculous' nature of the world as religious, related as it was, for him, with the 'meaning of life [and] the absolute good', reflective of a 'tendency of the human mind' which he reported himself as 'respecting deeply. ${ }^{16}$ Likewise, the practices through which receptivity to mystery is cultivated need not be overtly religious ones - taking liturgical or sacramental forms, say - but can include, as they do for Cooper, practices such as aesthetic appreciation, philosophical reflection, or engagement with the natural world. Indeed, Cooper has argued that gardening, uniquely premised as it is upon the co-dependence of 'human creative activity [and] the natural world, can, if reflectively engaged in, afford insights into one's 'relationship to mystery'. ${ }^{17}$

These three features converge in the claim that human beings can enjoy and cultivate receptivity to mystery through reflective engagement in certain practices. Mystery, then, should be understood less as a taken-forgranted feature of human life, but rather a cultivated feature of certain ways of life. Perhaps certain persons can enjoy a sense of mystery even in the absence of any of the requisite ways of life - just as even the most philistine ecophobe may occasionally be moved by an instance of natural beauty but that sense of mystery will be unlikely to be able to sustain the 'moral and spiritual transformation' which Cooper and Cottingham emphasise.

The edifying potential of a sense of mystery is premised upon the deep and sustained cultivation of one's receptivity to it. That will require, in Cottingham's words, 'initiation' into a 'community of praxis', participation in 'structured activities and performances', both private and social, which themselves enjoy 'continuity with a tradition', itself 'inherited from the past' and entrusted to the future. ${ }^{18}$ Cooper offers a parallel thought in a discussion of experiences of new or novel beauties, those of alien cultures, say: the appreciation of those beauties requires 'initiation into traditions, practices and ... contexts' which 'allow' those previously 'occluded' beauties to 'become visible', and such initiation demands 'effort, imagination, and intelligence', and so is 'educative' and 'improving.' ${ }^{19}$ A sense of mystery may therefore be a native feature of

${ }^{16}$ Ludwig Wittgenstein. 'A Lecture on Ethics', The Philosophical Review, 74 (1965), 3-12. Quotation from p. 12.

${ }^{17}$ Cooper, A Philosophy of Gardens (Oxford: Clarendon Press, 2006), pp. 135 and 145.

${ }^{18}$ Cottingham, The Spiritual Dimension, pp. 35, 103, 164, 144.

${ }^{19}$ Cooper, 'Edification and the Experience of Beauty', in Wang Keping (ed.), Diversity and Universality in Aesthetics (Beijing: Institute for Transcultural Studies, 2010), pp. 62-80. Quotation taken from pp.63-64. 
human beings - our 'natural birthright' - but the cultivation of that sense will, in most cases, require sustained and reflective practical engagement, resulting in an edifying 'moral and spiritual transformation'.

I draw two points from these remarks on the cultivation of receptivity to mystery. The first is that such receptivity must be actively and practically cultivated. Although it may be a feature of our 'natural birthright', it still requires sustained effort to cultivate it, just as a talent - musical or athletic, say - requires disciplined practice to draw out and develop. The second is that receptivity must be sustained, both practically and reflectively; hence Cottingham's call to religious persons to cultivate the virtues of 'faith and hope' which 'sustain our energies and keep alive our hopes', and Cooper's reminder that it is only through 'sufficient effort, engagement, openness and patience' that a person can 'achieve an attunement to mystery. ${ }^{20}$

\section{LOSS OF RECEPTIVITY TO MYSTERY}

Cooper and Cottingham indicate that receptivity to mystery requires reflective and practical activities aimed at moral and spiritual transformation. The relevant 'spiritual praxis' or 'comportments' can, however, fail to obtain for one of two related reasons. A person can fail to initiate or to persist in the practices which are necessary for its cultivation - perhaps like the person who either lacks a musical talent in the first place or who has it but fails to develop it, perhaps through laziness or indifference. A latent sense of mystery may be part of our 'natural birthright', but, without edifying practical and reflective effort, will remain at the level of a latent sensibility.

The question of why a person may fail to cultivate their receptivity to a sense of mystery is a complex one, whose immense scope is indicated by Charles Taylor's vast and magisterial book A Secular Age. ${ }^{21}$ But a necessary precondition of the cultivation of receptivity to mystery - of the sort described by Cooper and Cottingham - is surely that a person is convinced, or at least willing to consider, that such receptivity is both intelligible and attractive. Unless a person is open to the possibility of experiences of mystery, in the first place, and to cultivating the requisite

${ }^{20}$ Cottingham, The Spiritual Dimension, pp. 125, 172. Cooper, 'Living with Mystery', p. 11.

${ }^{21}$ Charles Taylor, A Secular Age (Cambridge, Mass.: Harvard University Press, 2007). 
receptivity to them, in the second, they will not - and indeed cannot take the decision to begin initiation into the practices through which such receptivity is cultivated. The demanding nature of such cultivation is stressed by all of those religious and philosophical traditions within which a sense of mystery plays an integral role; the complex pedagogical and philosophical practices of Zen Buddhism are perhaps the best example of such demanding practices of cultivation.

Cooper and Cottingham clearly regard a sense of mystery as something of immense moral and spiritual significance. A person who lacks receptivity to mystery is, for that reason, prevented from having experiences of immense moral and spiritual significance, rather than just missing out on certain rare but pleasant experiences, like the eating of a rare confectionary or hearing a rarely-performed piece of music. The life of a person who never has the good fortune to eat plum pudding is not substantially impoverished by virtue of that fact, whereas a life lacking in at least occasional experiences of mystery certainly is. But a person who judges that experiences of mystery - of Wordsworth's 'sense sublime', say - are merely something pleasing but inessential, will hardly be compelled to take seriously the demanding task of cultivating a receptivity to them. For such persons will regard a sense of mystery as some regard seeing Niagara Falls or swimming with dolphins; very nice if you manage it, but no great loss to your life if you don't.

Such lack of receptivity to mystery may be a native feature of the persons who lack it. Much as some people have no especial interest in music or sex, an indifference to experiences of mystery may simply be a feature of their character, peculiar as it may seem to any music lovers or romantic couples they report their indifference to. A life without music is not, pace Nietzsche, a mistake; not, at the least, for everyone, for there are persons who evince no especial love of music - or of art or sex or animals - but whose lives are, at least by their own lights, satisfying and fulfilling ones. To my mind, the life of a person who is not receptive to experiences of mystery is not, therefore, by definition a peculiar or impoverished one, at least in cases where that lack of receptivity is a native feature of their character or constitution. Perhaps those are William James's 'healthyminded' people, who lack any sense of the world as 'strange [or] uncanny', such that no sense of mystery - nor the need for one - can obtain. ${ }^{22}$

${ }^{22}$ William James, The Varieties of Religious Experience (New York: Longman, Green and Co., 1902), p. 151. 
I will not consider the question of whether a person ought to cultivate a sense of mystery. Perhaps such persons should not arouse our concern, even if their lives may prove inscrutable or perplexing to those for whom a sense of mystery is integral. But, equally, perhaps not. ${ }^{23}$

Concern should arise, however, concerning persons whose lack of receptivity to mystery may be attributable to more contingent factors. To recall the earlier example of the person with no love of music, their indifference may be native, if it really is the case that Mozart and Bach simply do not engage their interests or arouse their passions. But suppose that their indifference to music is, rather, the result of their growing up within a rabidly philistine household, within which a love of music was dismissed as snobbish indulgence or intolerable ponciness. This would not be a case of a natural lack of receptivity, but an artificial or induced one and therefore not one which would otherwise have come to shape that person's life. Such was the case with John Stuart Mill who famously found the 'states of feeling' suppressed by his rigid education restored by his reading of Wordsworth's poetry, such that he could 'find meaning in ... things' - like nature and art - previously rendered opaque, and whose absence, moreover, resulted in his nervous breakdown. ${ }^{24}$

\section{THE SCIENTISTIC STANCE}

The artificial induction of a lack of receptivity to experiences of mystery could take a variety of forms. A person may have the bad fortune to live in an intensely oppressive society, in which opportunities for engagement with art, nature, or religious practice are either minimised or co-opted for ideological purposes. The French Catholic philosopher and existentialist Gabriel Marcel took this line. A 'man cannot be free', he wrote, unless he is 'linked with that which transcends him', either through 'official and canonical' religion or in 'paint, or stone, or music'. A society systematically stripped of the possibilities for aesthetic or religious activities of these sorts is therefore one in which our 'relationship to the transcendent' cannot be 'experience[d] in the most authentic and profound way. ${ }^{25}$ Perhaps the receptivity to mystery of those persons has

\footnotetext{
${ }^{23}$ See further Ian James Kidd, 'Is Naturalism Bleak?', Environmental Values, forthcoming.

${ }^{24}$ John Stuart Mill, Autobiography and Literary Essays, Jack Stillinger (ed.) (London: Taylor and Francis, 1981), p. 150.

${ }^{25}$ Gabriel Marcel, Man Against Mass Society, trans. G. S. Fraser (Chicago: Henry Regnery Company, 1962), p. 16.
} 
been atrophied through neglect and underuse, or simply been crushed by forms of physical and psychological oppression.

Such cases of spiritually oppressive societies are depressingly easy to provide, but the loss of receptivity is hardly confined to them. Modern liberal societies afford enormous freedoms of religious belief and observance, yet many of their members evince no especial receptivity to mystery. A defining feature of those societies is, as Charles Taylor has observed, that religious belief is 'no longer axiomatic', that faith, in whatever religion, is 'one human possibility among others', alongside a spectrum of agnostic and atheistic alternatives. ${ }^{26}$ Although many factors contributed to what Taylor calls a change in the 'conditions of belief [and] experience', prime amongst them is the emergence of the modern sciences, which have gradually privileged a 'disengaged standpoint' upon the world. ${ }^{27}$

Taylor's arguments for that claim are too complex to be summarised here, but they find resonance with parallel claims made by Cooper and Cottingham. Throughout their work, each criticises what I will call the scientistic stance, a powerful and prevailing feature of much contemporary academic and popular culture which, they argue, is eroding our receptivity to mystery. The term 'stance' is here used in the technical sense articulated by Bas van Fraassen, to refer to an 'attitude, commitment, approach [or] cluster of such', possibly but not necessarily including certain beliefs, which constitutes a certain implicit conception of what the world is like, one which helps to pre-structure our experience of and engagement with it. ${ }^{28}$ A scientistic stance reflects a sense of the 'exclusive sufficiency' of natural scientific descriptions of reality, and is to be contrasted with what van Fraassen calls a stance of 'abiding wonder' at the world; a sense that the world is not exhausted by scientific description. ${ }^{29}$

The justification for nominating the scientistic stance is that, although many attitudes can contribute to a loss of receptivity to mystery, not all of those attitudes are either current within modern societies, or regarded as plausible and persuasive within it. A scientistic stance, of course, is, being both aligned with central features of 'late modern' societies - such as an enthusiasm for technology - and also incorporated into its sensus communis or worldview.

\footnotetext{
${ }^{26}$ Taylor, A Secular Age, p. 4 passim.

${ }^{27}$ Taylor, A Secular Age, pp. 4 and 11.

${ }^{28}$ Bas van Fraassen, The Empirical Stance (New Haven: Yale University Press, 2002), pp. 47-48.

${ }^{29}$ Fraassen, The Empirical Stance, pp. 47-155f.
} 
Cooper and Cottingham both identify the scientistic stance as a prime cause of the loss of receptivity to mystery in contemporary societies. A person in hock to the scientistic stance employs what Cottingham calls a 'schematic picture of truth and reality' which, though difficult to precisely characterise, 'exerts an increasingly powerful influence, in a host of rational and pre-rational ways, on how many people feel able to interpret the world around them. ${ }^{30}$ Those influences can be detrimental, for, as Cooper argues, such scientism surely counts among the many 'attitudes, ambitions and stances' which are, for varying reasons, 'not consonant with a sense of mystery.' ${ }^{31}$ So although the scientistic stance is not unique in its capacity to contribute to a loss of receptivity to mystery, it surely bears responsibility for much of the loss within modern societies.

A main reason why the scientistic stance undermines one's receptivity to mystery was identified by Wittgenstein, a figure invoked by both Cooper and Cottingham. The 'disastrous thing about the scientific way of thinking', complained Wittgenstein, is not simply that it 'today possesses the whole world', but also that it encourages those who embrace it to 'respond to every disquietude with an explanation. ${ }^{32}$ The scientistic stance denies the possibility of mystery in the strong sense defended by Cooper by reducing it to 'merely that [which] has not yet been explained by science, thereby excluding the possibility of an ineffable, undiscursible reality. ${ }^{33} \mathrm{~A}$ certain sense of mystery is permitted, but that concession is compromised by the qualifying conviction that any such sense is destined to be dissolved by ongoing scientific enquiry, perhaps in a future 'Theory of Everything. A sense of mystery of the strong sort described by Cooper and Cottingham is therefore ruled out and reduced to a transitory feature of our life in the world, rather than an irreducible and enduring aspect of it. ${ }^{34}$

\footnotetext{
${ }^{30}$ Cottingham, The Spiritual Dimension, p. 108.

${ }^{31}$ Cooper, 'Living with Mystery', p. 6.

${ }^{32}$ Quoted in James Carl Klagge, Wittgenstein in Exile (Boston, Mass.: MIT Press, 2010), p. 129.

${ }^{33}$ Wittgenstein, 'A Lecture on Ethics', The Philosophical Review, 74 (1965), 10-11.

${ }^{34}$ Might one interpret the rhetoric of awe and wonder popular amongst many science writers - like Carl Sagan and Richard Dawkins - as reflections of a sense of mystery in this sense? I argue not, for two reasons. The first is that those writers allow the possibility, in principle or in practice, of descriptions of reality 'in itself' - perhaps the result of a future physics - and so rule out the strong sense of mystery being discussed here. The second is that those writers' sense of mystery does not tend to initiate moral and spiritual transformation in the way that the strong sense does; certainly the attitudes of
} 
My concern is therefore that the adoption of a scientistic stance will reduce, in part or in whole, a person's capacity to cultivate receptivity to experiences of mystery. Such loss of receptivity can take a variety of forms - from a total lack of native receptivity in one case to the atrophy of a dormant sense in another - and these are discussed in the next section. A scientistic person may find that the 'picture' of the world they implicitly operate with finds no room for mystery, so no sense of it obtains, nor can the possibility of that sense be entertained. Unless the world is pictured in such a way that mystery is possible - perhaps, following Heidegger, in terms of an ineffable 'source' or 'ground' of being - then experiences of mystery will find little purchase. The concern shared by Cooper and Cottingham is that the forms of scientistic stance which are both prevalent and powerful within modern societies tend to militate against such openness, thereby contributing to a loss of receptivity to mystery.

\section{SCIENTISM AND LOSS OF RECEPTIVITY TO MYSTERY}

There are many ways in which a scientistic stance can contribute to a loss of receptivity to mystery. Cooper and Cottingham identify several of these, which I will present in ascending order, ranging from a person's own receptivity to mystery to their attitudes towards those figures and traditions that report and incorporate a sense of mystery. It is worth noting that one might suggest that some persons simply lack any receptivity to mystery, so that a scientistic stance does not, in fact, affect them; that may be so, but it strikes me as more plausible to suppose that receptivity to mystery, just like appreciation of beauty or goodness, is the 'default option' for most persons. Understanding those persons who seem to have a native lack of receptivity to mystery - let alone beauty or goodness - is a task for another time.

There are four ascending ways in which the adoption of a scientistic stance may occlude a person's native receptivity to mystery. First, a scientistic stance may prevent a person from 'responding' to experiences of mystery in the necessary way, perhaps because of their

writers like Sagan and Dawkins towards religion do not evince the sort of edification that Cooper and Cottingham, amongst others, describe. For a useful discussion of such rhetoric, see John Haught, Is Nature Enough? Meaning and Truth in the Age of Science (Cambridge: Cambridge University Press, 2006). 
conviction that reality lacks anything like a 'transcendent' dimension. That person will, argues Cottingham, be able to respond to the world only as a 'sequence of brute facts', thereby remaining closed to the possibility of an 'intimation' of anything beyond it. ${ }^{35}$ Certain 'modes of receptivity' are thereby ruled out, including Bishop Berkeley's seeing the 'mighty frame of the world' as the 'mind of [an] eternal spirit', or Martin Heidegger's, in regarding nature as something which 'assails and enthrals us' - rather than being mere particles in motion - to cite two examples offered by Cooper. ${ }^{36}$ Since an experience of mystery is, in part, constituted by one's appropriately responding to it, any inability to respond thereby compromises the possibility of the experience; and so, as Cooper puts it, a scientistic stance occludes our experience of mystery because it 'obstructs the having of it. ${ }^{37}$

Second, a scientistic stance diminishes our receptivity to mystery by undermining our capacity to openly engage with those persons who are, in fact, possessed of that receptivity. Many persons who are receptive to mystery nonetheless fail to have strong experiences of it, yet are able to take seriously the testimonies of those who do - such as Teresa of Avila or the Sufis; so one may be receptive to others' experiences of mystery, even in the absence of any experiences of one's own. But for a person operating with a scientistic stance, such testimonies are automatically reinterpreted and downgraded in scientistic terms; hence the neurobiologist Vilayanur Ramachandran's insistence that 'our mental life - all our feeling and emotions' are, at base, 'simply the activity of these little specks of jelly in our heads, in our brains. ${ }^{38}$ A person persuaded of this is thereby debarred from experiencing testimonies to experiences of mystery as just that experiences of mystery - for they will inevitably be 'translated' into other terms (those of neurobiology, in Ramachandran's case).

This loss of receptivity to testimonials of experiences of mystery generates specific problems for Cooper and Cottingham because it

${ }^{35}$ Cottingham, The Spiritual Dimension, p. 48.

${ }^{36}$ George Berkeley, Philosophical Writings, T. Jessop (ed.) (London: Nelson, 1952), p. 148. Martin Heidegger, Being and Time, trans. J. Macquarrie and E. Robinson (Oxford: Blackwell, 1980), p. 100. For a sophisticated account of Heidegger's views on the role played by science in the occlusion of certain ways of experiencing nature, see David E. Cooper, 'Heidegger on Nature', Environmental Values, 14 (2002), 339-351.

${ }^{37}$ Cooper, The Measure of Things, p. 341.

${ }^{38}$ V. S. Ramachandran, A Brief Tour of Human Consciousness (New York: Pi Press, 2005), p. 3. 
challenges their specific proposals for cultivating a sense of mystery, which constitute the third and fourth ways that a scientistic stance can undermine receptivity.

Third, a scientistic stance prevents a person from being able to regard certain people - either poets, philosophers, or religious figures - as what Cooper calls 'heroes'. These heroes act as guides or exemplars, for, as Cooper rightly remarks, a person may have no idea about what a sense of mystery is or how certain practices may provide intimations of it. Such persons in that state of uncertainty will, quite naturally, try to seek out a hero, a person - real or fictional, historical or contemporary - whose life seems to 'answer to [and] be given shape by' their sense of mystery. ${ }^{39}$ Yet, of course, one will find it difficult, if not impossible, to invest 'resolute confidence' in such people if one is, to quote Wittgenstein, persuaded that 'poets [and] musicians' only exist to 'entertain' rather than to 'teach', and so many potential 'heroes' - including those deeply attuned to a sense of mystery - are thereby lost to them. ${ }^{40}$

Fourth, a scientistic stance prevents a person from participating in the 'communities of praxis' which Cottingham describes. It is only through such practical and social immersion that one can begin the 'process of growth and transformation' which is the 'catalyst' for what I have called receptivity to mystery. ${ }^{41}$ Yet that becomes impossible if one subscribes to the view that the praxis of that community is unwarranted nonsense, for then participation in those practices, and the surrounding community, becomes absurd. An illustrative example is Owen Flanagan's recent call for a 'naturalisation' of Buddhism, purging it of 'mind-numbing and wishful hocus pocus', like karma and rebirth. ${ }^{42}$ If one takes this proposal seriously, then the practices and traditions of Buddhism are thus impugned, for their component metaphysical claims will appear, as they do to Flanagan, as 'silly superstitions', such that it becomes difficult, if not impossible, to sincerely participate in them. For it is not at all clear either that concepts like karma are inessential features of Buddhist philosophy or that the integrity of its ethical teachings would survive their removal. ${ }^{43}$

\footnotetext{
${ }^{39}$ Cooper, 'Living with Mystery', p. 12.

${ }^{40}$ Wittgenstein, Culture and Value, trans. Peter Winch. (Oxford: Blackwell, 1980), p. 42.

${ }^{41}$ Cottingham, The Spiritual Dimension, pp. 143 and 152.

${ }^{42}$ Owen Flanagan, The Bodhisattva's Brain: Buddhism Naturalised (Cambridge, Mass.: MIT Press, 2011), p. 3 passim.

${ }^{43}$ See the interesting discussion of Flanagan's naturalised Buddhism at the 'Buddhist Ethics Naturalised' panel at the Contemporary Perspectives on Buddhist Ethics conference,
} 
Once these points are appreciated, a fifth emerges, namely that a scientistic person gradually loses their sense not only of mystery, but of what Paul Feyerabend called the 'abundance' of the world. This refers to the fact of their being a rich diversity of ways of conceiving of and comporting oneself within it, through which one can come to recognise the 'richness of Being'. Such abundance can be lost through an insistence upon the exclusive truth of some one set of conceptions of reality, such as those of the sciences, when it is better, argued Feyerabend, to cultivate a sense of 'spontaneous tolerance' towards alternative traditions and a 'quieter, more wondering attitude' towards the world. ${ }^{44} \mathrm{~A}$ person possessed of this attitude will revoke the scientistic stance and instead strive to learn 'from the sciences [and] also from the humanities[,] religion and from ... ancient traditions', consonant with Cooper's and Cottingham's call to re-engage with those spiritual traditions within which a sense of mystery plays a central role. ${ }^{45}$ Indeed, Feyerabend himself argued that reality in itself - what he called 'Being' - is 'ineffable' and unknowable, although 'abundance' in his sense does not necessarily entail that; one can be open to the idea of there being alternative accounts of reality without also subscribing to a doctrine of mystery, even if Feyerabend, for the record, did. ${ }^{46}$

These five ways in which a scientistic stance can contribute to the loss of receptivity to mystery are related in a variety of ways, most often in a mutually reinforcing manner. My treatment of these five ways is not exhaustive, but nor need it be for present purposes. Cooper and Cottingham may, of course, disagree on the details of these ways of reducing receptivity to mystery; however, both agree that a person operating with a scientistic stance may be rendered unreceptive to both their own experiences of mystery and those of others, including the religious and philosophical figures and traditions within which those experiences play a central role.

Columbia University, 6-7 October 2011. A podcast of that panel is available online at $<$ http://www.cbs.columbia.edu/buddhist_ethics/panel-one.htm $>$. I am grateful to Jan Westerhoff for a helpful discussion of Flanagan's views.

${ }^{44}$ Paul Feyerabend, Conquest of Abundance: A Tale of Abstraction versus the Richness of Being, Bert Terpstra (ed.) (Chicago: University of Chicago Press, 2001), p. xi.

${ }^{45}$ Paul Feyerabend, Against Method. 3rd ed. (London: Verso, 1993), p. 249.

${ }^{46}$ See further Ian James Kidd, 'Feyerabend on the Ineffability of Reality', Models of God and Alternative Ultimate Realities, Asa Kasher and Jeanne Diller (eds.) (Dordrecht: Kluwer, 2012). 


\section{CONCLUSIONS}

The aim of this paper was to explore the theme of loss of receptivity to mystery common to Cooper and Cottingham. I argued that both identify the prevalence of a scientistic stance as a prime cause of the loss of such receptivity in modern societies, since it distorts a person's capacity to properly respond to their own experiences of mystery and to engage openly in the practices and with the traditions which the cultivation of a sense of mystery requires. It is worth closing by considering two possibilities - one each from Cooper and Cottingham - for how one might challenge that scientistic stance.

The first is that one could restore appreciation of the traditions within which doctrines of mystery have enjoyed a central role. Cooper writes of a 'modesty or humility' which attends the recognition that 'philosophers from earlier times, and different cultures' would regard many of our beliefs - such as scientific realism - as 'incredible. ${ }^{47}$ Although such appreciation does not in itself necessitate a commitment to a doctrine of mystery, it would surely encourage an abandonment of scientistic insistence on the immaturity or absurdity of those traditions. Such recognition involves humility because it requires us to concede that our own achievements - the scientific Weltbild for example - should not blind us to the possibility, indeed the fact, of alternative conceptions of reality and forms of life.

The second strategy for restoring receptivity to mystery is offered by Cottingham's proposals for a reorientation of the philosophy of religion in a 'humane' direction. ${ }^{48}$ Although what Brian Leiter calls the 'naturalistic turn' has produced much valuable work, there are good reasons to suppose that its capacity to provide the necessary resources to explore and understand the domain of the religious is reaching its limits. Cottingham proposes that a 'humane turn' is needed, whereby philosophers can 'address ... questions about human self-understanding' using 'methods and resources' quite distinct from those typical of the naturalistic turn. Indeed, Cottingham judges that 'the adoption

${ }^{47}$ David E. Cooper and Peter S. Fosl, Philosophy: The Classic Readings. (Oxford: Wiley-Blackwell, 2010), p. xxiv.

${ }^{48}$ John Cottingham, 'What is Humane Philosophy and Why is it At Risk?', in Anthony O'Hear (ed.), Conceptions of Philosophy (Cambridge: Cambridge University Press, 2009), pp. 233-255. On the idea of humane philosophy as a response to scientism, see Ian James Kidd, 'Humane Philosophy and the Question of Progress', Ratio, XXV, no. 3 (2012), 277-290. 
of a humane approach' is an 'essential prerequisite' of a revitalised philosophy of religion: one liberated from scientistic preconceptions which distort and occlude much about religious life. ${ }^{49}$

These two proposals may perhaps raise as many problems as they might resolve. Certainly Cooper and Cottingham set themselves ambitious tasks, especially since the success of their proposals is crucially premised upon a reassessment of the naturalistic orthodoxy of contemporary mainstream philosophy. But when one considers that such self-reflexive criticism is a central feature of the philosophical enterprise, and that the sentiments expressed by Cooper and Cottingham are aligned with ancient and venerable spiritual traditions, a call to take seriously these claims of loss of receptivity to mystery appears neither unwarranted nor absurd. ${ }^{50}$

${ }^{49}$ Cottingham, The Spiritual Dimension, p. ix.

${ }^{50}$ I offer my thanks to David E. Cooper and John Cottingham for inspiring my thoughts on this topic and for their kind participation in the 'Mystery, Humility, and Religious Practice' workshop, and to Guy Bennett-Hunter, Arlette Frederik, Thomas Greaves, Jan Westerhoff, and Jonathon Winthrop for their very helpful comments on this paper. 